\title{
ANALYSIS OF IMPLEMENTATION THE THEMATIC INTEGRATED LEARNING SCIENCE IN THE JUNIOR HIGH SCHOOL (SMP) NEGERI 1 TAMBUSAI
}

\author{
Nurhikmah Sasna Junaidi ${ }^{* 1}$, Afdhal Ridho ${ }^{2)}$ \\ ${ }^{1)}$ Physics Education, University of Pasir Pengaraian \\ 2) Junior High School (SMP) Negeri 1 Tambusai \\ e-mail: nurhikmahsasnajunaidi@gmail.com \\ afdha191ridho@gmail.com
}

\begin{abstract}
This study aimed to describe the implementation of thematic integrated science learning at SMP N 1 Tambusai. The research method was quantitative descriptive research. The data used as a result were in the form of filling questionnaire data by teachers. Based on the results, it was found that the planning aspects of the integrated science learning plan with a percentage of $75 \%$ was good, the implementation aspect of integrated science learning with a percentage of $72.5 \%$ was enough, and aspects of assessment learning process and results with a percentage of $77.5 \%$ was good. Thus, the average of whole aspect was $75 \%$ categorized as good. So, the implementation of thematic integrated science learning at SMP N 1 Tambusai has been carried out sufficiently, both in accordance with the objectives of the 2013 Curriculum.
\end{abstract}

Keywords: Integrated Science, 2013 Curriculum, Thematic

\section{ANALISIS KETERLAKSANAAN PEMBELAJARAN IPA TERPADU TEMATIK DI SMPN 1 TAMBUSAI}

\author{
Nurhikmah Sasna Junaidi ${ }^{* 1)}$, Afdhal Ridho ${ }^{2)}$ \\ ${ }^{1)}$ Pendidikan Fisika, Universitas Pasir Pengaraian \\ ${ }^{2)}$ Sekolah Menengah Pertana Negeri 1 Tambusai
}

\begin{abstract}
Abstrak
Penelitian ini bertujuan untuk mendeskripsikan keterlaksanaan pembelajaran IPA terpadu tematik di SMPN 1 Tambusai. Metode penelitian yaitu penelitian deskriptif kuantitatif. Data yang digunakan sebagai hasil penelitian berupa data hasil pengisian angket oleh guru. Dari hasil penelitian diperoleh bahwa aspek perancangan perencanaan pembelajaran IPA terpadu dengan persentase $75 \%$ dikategorikan baik, aspek pelaksanaan pembelajaran IPA terpadu dikategorikan cukup dengan persentase $72,5 \%$, dan aspek penilaian proses dan hasil belajar dengan persentase $77,5 \%$ dan dikategorikan baik. Sehingga rata-rata keseluruhan aspek yaitu $75 \%$ dikategorikan baik. Sehingga keterlaksanaan penerapan pembelajaran IPA terpadu tematik di SMPN 1 Tambusai sudah dilaksanakan dengan baik sesuai dengan tujuan Kurikulum 2013.
\end{abstract}

Kata kunci: IPA Terpadu, Kurikulum 2013, Tematik 


\section{Pendahuluan}

Pembelajaran IPA di SMP menerapkan pembelajaran IPA terpadu yang secara utuh sesuai dengan Permendiknas No. 22 tahun 2006, Permendikbud No. 68 tahun 2013 dan Permendikbud No. 22 tahun 2016 tentang standar proses. Ketiga kebijakan ini menetapkan bahwa kurikulum dari KTSP sampai Kurikulum 2013 menerapkan mata pelajaran IPA dipelajari secara terpadu dan tematik. Tema merupakan pengikat untuk menghasilkan keterpaduan dalam pelajaran IPA (Yamin Martinis, 2006).

Pembelajaran IPA dapat menumbuhkembangkan kompetensi peserta didik pada ranah sikap, pengetahuan, dan keterampilan. Ketiga ranah kompetensi tersebut memiliki lintasan perolehan (proses psikologis) yang berbeda. Sebuah pengetahuan dapat diperoleh melalui aktivitas mengingat, memahami, menerapkan, menganalisis, dan mengevaluasi (Izzati et al., 2013).

Pembelajaran terpadu adalah sebagai kegiatan belajar mengajar dengan memadukan materi beberapa mata pelajaran dalam satu tema (Ujang Sukandi, et al., 2001). Pembelajaran IPA terpadu juga merupakan satu kesatuan ilmu yang menyajikan materi secara utuh pada bidang kajian IPA.

IPA terpadu memiliki tujuan untuk meningkatkan efisiensi dan efektivitas pembelajaran, meningkatkan minat dan motivasi, dan mencapai beberapa kompetensi dasar secara sekaligus (Trianto, 2012). Kompetensi-kompetensi dasar yang didapatkan dalam pembelajaran IPA terpadu tematik menjadikan peserta didik lebih menyukai dan mudah dalam menyelesaikan berbagai permasalahan IPA yang terjadi disekitarnya (Nurhikmah, 2017).

Pembelajaran tematik pada dasarnya adalah model pembelajaran terpadu yang menggunakan tema untuk mengaitkan beberapa mata pelajaran sehingga dapat memberikan pengalaman bermakna kepada siswa (Muhammad Abduh, 2014).

Pembelajaran tematik dapat diartikan sebagai suatu pembelajaran dengan mengintegrasikan materi beberapa mata pelajaran dalam satu tema/topik pembahasan. Disamping itu, pembelajaran tematik akan memberi peluang pembelajaran terpadu yang lebih menekankan pada partisipasi atau keterlibatan siswa dalam belajar.

Dasar menerapkan dan melaksanakan pembelajaran tematik, ada beberapa prinsip dasar yang perlu diperhatikan yaitu: 1) bersifat terintegrasi dengan lingkungan, 2) bentuk belajar dirancang agar siswa menemukan tema, dan 3) efisiensi waktu, beban materi, metode, dan penggunaan sumber belajar yang otentik (Sungkono, 2009).

Pembelajaran tematik terpadu merupakan pendekatan pembelajaran yang mengintegrasikan berbagai kompetensi dari berbagai mata pelajaran dalam berbagai tema (Permendikbud, 2014).

Pembelajaran IPA terpadu tematik hanya berlangsung disekitar tema sampai ditemukannya konsep-konsep pokok yang berkaitan dengan tema. Tema untuk pelajaran IPA terpadu disajikan dalam konteks sains, lingkungan, teknologi, dan masyarakat yang melibatkan peserta didik aktif didalam kelompok maupun mandiri (Trianto, 2012). Pemilihan tema yang dijadikan sebagai salah satu upaya untuk menjadikan pembelajaran IPA menjadi terpadu sebagai berikut (Daryanto, 2014): 1) Cara pertama, mempelajari kompetensi inti dan kompetensi dasar yang terdapat dalam masing-masing mata pelajaran, dilanjutkan dengan menentukan tema yang sesuai; 2) Cara kedua, menetapkan terlebih dahulu tema-tema pengikat keterpaduan, untuk menentukan tema tersebut, guru dapat bekerjasama dengan peserta didik, sehingga sesuai dengan minat dan kebutuhan anak; 3) Menerapkan prinsip penentuan tema yaitu: 1) memperhatikan lingkungan terdekat dengan peserta didik; 2) dari yang termudah menuju yang sulit; 3) dari yang konkrit menuju yang abstrak; 4) tema yang dipilih harus memungkinkan terjadinya proses berpikir pada diri peserta didik; 5) ruang lingkup tema disesuaikan dengan usia dan perkembangan peserta didik.

Tema dalam pembelajaran IPA dipadukan dengan menerapkan model terpadu agar dapat terlaksana dengan baik. Menurut Fogarty (1991) terdapat sepuluh model pembelajaran untuk IPA terpadu, yaitu 1) the fragmented model (model terpisah-pisah); 2) the connected model (model terhubung); 3) the nested model (model tersarang); 4) the sequenced model (model terurut); 5) the shared model (model terbagi); 6) the webbed model 
(model terjaring); 7) the threaded model (model tertali); 8) the integrated model (model terpadu); 9) the immersed model (model terbenam); 10) the networked model (model jaringan).

Pemilihan tema yang dijadikan sebagai salah satu upaya untuk menjadikan pembelajaran IPA menjadi terpadu sebagai berikut (Daryanto, 2014): 1) Cara pertama, mempelajari kompetensi inti dan kompetensi dasar yang terdapat dalam masing- masing mata pelajaran, dilanjutkan dengan menentukan tema yang sesuai; 2) Cara kedua, menetapkan terlebih dahulu tema-tema pengikat keterpaduan, untuk menentukan tema tersebut, guru dapat bekerjasama dengan peserta didik sehingga sesuai dengan minat dan kebutuhan anak; 3) Menerapkan prinsip penentuan tema yaitu: a) memperhatikan lingkungan terdekat dengan peserta didik; b) dari yang termudah menuju yang sulit; c) dari yang konkrit menuju yang abstrak; d) tema yang dipilih harus memungkinkan terjadinya proses berpikir pada diri peserta didik; e) ruang lingkup tema disesuaikan dengan usia dan perkembangan peserta didik, termasuk minat, kebutuhan, dan kemampuannya; f) Tema yang dipilih bersifat menarik dan kebaharuan bagi peserta didik.

Adapun menurut La Iru (2012) Pembelajaran terpadu disebut juga dengan pembelajaran terintegrasi sebagai peristiwa atau eksplorasi autentik dari sebuah topik menjadi faktor pendorong dalam kurikulum. Dengan eksplorasi autentik, maka peserta didik dapat belajar proses dan materi yang berkaitan dengan wilayah kurikulum pada waktu yang bersamaan.

Eksplorasi autentik dalam pembelajaran IPA terpadu merupakan satu kesatuan pengalaman baru dari ilmu untuk menyajikan materi secara utuh pada bidang kajian IPA. Eksplorasi autentik dapat diperoleh dari sekolah.

Sekolah merupakan agen khusus sebagai sarana dalam memberikan kompetensi dasar pembelajaran IPA terpadu tematik dan tempat peserta didik menyelesaikan permasalahan IPA. Sesuai dengan standar nasional pendidikan, bahwa pembelajaran akan terlaksana dengan baik apabila dilakukan sesuai dengan standar yang telah ditetapkan sebagai acuan dasar. Namun, pembelajaran IPA yang terjadi di lapangan saat ini khususnya pelaksanaan pembelajaran belum sepenuhnya dilakukan sesuai dengan standar acuan dasar yang telah ditetapkan, salah satunya yaitu pembelajaran IPA masih dilaksanakan secara terpisah.

Proses pembelajaran IPA akan lebih bermakna apabila diberikan pengalaman langsung. Pembelajaran langsung mampu menyajikan kondisi belajar lebih alami sehingga hasil yang diperoleh maksimal. Karena belajar melalui media atau hal nyata lebih banyak melibatkan indera tubuh untuk berperan aktif dalam penyampaian informasi ke otak (Uus Toharudin et al., 2011). Dengan diberlakukannya Kurikulum 2013 telah memberikan rona yang berbeda terhadap pembelajaran IPA (Esmiyati, 2013).

Proses Pelaksanaan Kurikulum 2013 dapat dinilai dari beberapa aspek yaitu: (1) Perencanaan Pelaksanaan Pembelajaran IPA terpadu, (2) Pelaksanaan Pembelajaran IPA terpadu sesuai Kurikulum 2013, pembelajaran dilaksanakan secara terpadu tematik dan menerapkan pendekatan saintifik. Pembelajaran terpadu tematik dengan menerapkan model terpadu dan setiap pembelajaran dilaksanakan dengan pendekatan saintifik, dan (3) Penilaian proses dan hasil belajar IPA terpadu.

\section{Bahan dan Metode}

Penelitian ini merupakan penelitian deskriptif kuantitatif untuk mengetahui analisis keterlaksanaan pembelajaran IPA terpadu tematik di SMPN 1 Tambusai. Penelitian dilaksanakan pada bulan Januari-Februari 2018 di SMPN 1 Tambusai. Instrumen yang digunakan dalam penelitian untuk pengumpulan data berupa angket. Indikator yang dijabarkan pada setiap angket merujuk pada Permendikbud No. 22, 23, dan 24 tahun 2016 hasil modifikasi (Indah Ratnasari, 2016). Teknik analisis data untuk mengetahui keterlaksanaan pembelajaran IPA terpadu tematik menggunakan persamaan (1) berikut (Indah Ratnasari, 2016).

$$
\text { Nilai }=\frac{\text { skor diperoleh }}{\text { skor maksimum }} \times 100 \%
$$


Adapun kriteria penilaian merujuk pada Tabel 1 berikut.

Tabel 1. Kriteria penilaian

\begin{tabular}{cll}
\hline No & \multicolumn{1}{c}{ Nilai } & \multicolumn{1}{c}{ Peringkat } \\
\hline 1 & $90 \% \leq \mathrm{A} \geq 100 \%$ & Amat Baik (A) \\
2 & $75 \% \leq \mathrm{B} \geq 89 \%$ & Baik (B) \\
3 & $60 \% \leq \mathrm{C} \geq 74 \%$ & Cukup (C) \\
4 & $\mathrm{~K} \leq 60 \%$ & Kurang (K) \\
\hline
\end{tabular}

Pembelajaran Kurikulum 2013 di SMP dikatakan terlaksana dengan baik apabila hasil dalam pelaksanaannya mencapai $75 \%$.

\section{Hasil dan Pembahasan}

Hasil yang diperoleh dari penelitian yang dilakukan dengan tujuan akhirnya untuk mendeskripsikan hasil analisis keterlaksanaan pembelajaran IPA terpadu tematik di SMPN 1 Tambusai. Adapun hasil keterlaksanaan pembelajaran IPA terpadu tematik pada Kurikulum 2013 sesuai pada Tabel 2.

Tabel 2. Hasil Keterlaksanaan Pembelajaran IPA Terpadu Tematik pada Kurikulum 2013

\begin{tabular}{|c|c|c|}
\hline Aspek Penilaian & Hasil & Kategori \\
\hline $\begin{array}{l}\text { Perencanaan } \\
\text { Pelaksanaan } \\
\text { Pembelajaran IPA } \\
\text { terpadu tematik }\end{array}$ & $75 \%$ & $\begin{array}{c}\text { Baik } \\
\text { (B) }\end{array}$ \\
\hline $\begin{array}{l}\text { Pelaksanaan } \\
\text { Pembelajaran IPA } \\
\text { Terpadu tematik }\end{array}$ & $72,5 \%$ & $\begin{array}{l}\text { Cukup } \\
\text { (C) }\end{array}$ \\
\hline $\begin{array}{l}\text { Penilaian Proses dan } \\
\text { Hasil Belajar IPA } \\
\text { Terpadu tematik }\end{array}$ & $77,5 \%$ & $\begin{array}{l}\text { Baik } \\
\text { (B) }\end{array}$ \\
\hline Rata- rata & $75 \%$ & $\begin{array}{l}\text { Baik } \\
\text { (B) }\end{array}$ \\
\hline
\end{tabular}

Tabel 2 menjelaskan bahwa pelaksanaan pembelajaran IPA terpadu di SMPN 1 Tambusai dengan Kurikulum 2013 dari setiap aspek yang dinilai dapat dikategorikan baik dengan nilai rata-rata keseluruhan aspek yaitu $75 \%$.

Perencanaan pelaksanaan pembelajaran IPA terpadu tematik dinilai dari ketersediaan dan kesesuaian RPP sesuai dengan pedoman. Pada proses perencanaan pembelajaran IPA terpadu tematik guru telah menyusun RPP dengan format yang sesuai dengan Kurikulum 2013, terdiri dari identitas sekolah, mata pelajaran, kelas/semester, materi pokok, alokasi waktu, kompetensi inti, KD dan indikator, tujuan pembelajaran, materi pembelajaran, langkah-langkah pembelajaran/ kegiatan pembelajaran, metode pembelajaran, media pembelajaran, sumber belajar, penilaian, dan tema terpadu pembelajaran.

Kesesuaian dengan langkah-langkah pembelajaran saintifik serta rencana penilaian yang sesuai penilaian autentik telah dicantum kan. Penyusunan RPP didasarkan pada silabus Kurikulum 2013 dan menyusun langkahlangkahnya berdasarkan buku pegangan Kurikulum 2013.

Perencanaan pelaksanaan pembelajaran IPA terpadu tematik dapat dikategorikan baik dengan nilai $75 \%$. Dalam penyusunan indikator dan tujuan pembelajaran sesuai dengan permintaan dari Kurikulum 2013 yaitu terpadu namun belum tematik.

Indikator yang dijabarkan masih seperti mata pelajaran IPA Fisika dan IPA Biologi bukan IPA terpadu dan tematik. Sehingga perlu dilakukan bimbingan dalam penjabaran indikator terpadu tematik dan tema dalam RPP. Perencanaan pelaksanaan pembelajaran yang dijabarkan sesuai dengan pedoman akan menjadikan pelaksanaan akan lebih efektif.

Hal ini sependapat dengan penelitian Hendra Jati Puspita (2016) yang menyatakan bahwa perencanaan yang dibuat dituangkan ke dalam rencana pelaksanaan pembelajaran (RPP). Setiap RPP mengacu dari silabus atau kurikulum yang berlaku, kemudian dikembangkan sesuai dengan kondisi disatuan pendidikan. Perencanaan pelaksanaan pembelajaran IPA yang sesuai dengan kriteria minimal pada RPP dapat dikatakan sudah mencapai kriteria minimal.

Sesuai dengan penelitian yang dilakukan oleh Friski Herina Fitriani (2013) tentang 
pengembangan media pembelajaran IPA terpadu berbasis komputer pada tema bunyi melalui lesson study untuk kelas VIII menyatakan bahwa pembelajaran IPA terpadu dengan tema bunyi yang dikaji dengan penerapan lesson study yang dikembangkan efektif diterapkan sebagai media pembelajaran IPA terpadu berbasis komputer pada tema bunyi untuk kelas VIII dan dapat meningkatkan ketuntasan klasikal 88,89\%.

Proses pelaksanaan pembelajaran IPA terpadu tematik di SMPN 1 Tambusai dikategori cukup dengan nilai 72,5\%. Dalam pelaksanaan sudah sebagian besar melaksanakan pembelajaran sesuai dengan tujuan Kurikulum 2013 yaitu pembelajaran yang mengajak peserta didik untuk mencari tahu dan menyelesaikan permasalahan IPA terpadu yang diberikan. Proses pelaksanaan pembelajaran IPA terpadu tematik terdiri dari kegiatan pendahuluan, kegiatan inti, dan kegiatan penutup.

Pada kegiatan pendahuluan guru sudah memberikan stimulus kepada siswa untuk berdo'a, mengaitkan materi yang sudah dipelajari dengan materi baru. Pada kegiatan inti terlihat sekolah sudah menerapkan praktikum dan pembelajaran dilapangan serta metode ceramah sudah tidak dominan digunakan dalam kegiatan inti, hanya pada kegiatan penutup sebagai konfirmasi. Namun, pada kegiatan inti pendekatan saintifik yang merupakan ciri khusus dari Kurikulum 2013 belum sepenuhnya digunakan, masih ada beberapa langkah dari pendekatan saintifik yang tidak dilaksanakan. Jika pendekatan saintifik dilaksanakan semua langkahnya yaitu mengamati, menanya, mencoba, menganalisis, dan mengkomunikasikan, maka pembelajaran lebih baik lagi (Nurhikmah, 2017).

Wiwik Nurul Hayati (2012) pada pengelolaan pembelajaran tematik di SD Djama'atul Ichwan Surakarta menyatakan bahwa kelemahan dan kelebihan media yang digunakan dalam pembelajaran tematik, tidak menjadi alasan bagi guru untuk memaksimalkan upaya guru memberikan pelayanan pembelajaran yang terbaik. Guru yang memiliki tingkat efikasi tinggi tidak memberikan prediksi yang bersifat negatif berdasarkan perilaku siswa. Hasil ini mengindikasikan akan pentingnya kompleksitas karakteristik yang dibawa masing-masing siswa dalam pembelajaran.

Hasil pelaksanaan pembelajaran Pembelajaran IPA pada hakikatnya meliputi empat unsur utama yaitu: 1) sikap: rasa ingin tahu tentang benda, fenomena alam, makhluk hidup, serta hubungan sebab akibat yang menimbulkan masalah baru yang dapat dipecahkan melalui prosedur yang benar; IPA bersifat open ended, 2) proses: prosedur pemecahan masalah melalui metode ilmiah; metode ilmiah meliputi penyusunan hipotesis, perancangan eksperimen atau percobaan, evaluasi, pengukuran, dan penarikan kesimpulan, 3) produk: berupa fakta, prinsip, teori, dan hukum, dan 4) aplikasi: penerapan metode ilmiah dan konsep IPA dalam kehidupan sehari-hari. Empat unsur utama IPA ini seharusnya muncul dalam pembelajaran IPA (Nahampun Jeperis, 2013).

Aspek penilaian keterlaksanaan pembelajaran IPA terpadu tematik dengan Kurikulum 2013 yaitu penilaian proses dan hasil belajar dengan persentase $77,5 \%$ dan dikategorikan baik. Penilaian proses yang dilakukan guru sudah menggunakan format penilaian yang tersedia pada buku pedoman.

Hasil belajar IPA yang diperoleh dikategorikan baik dengan hampir 75\% peserta didik mampu mengikuti pembelajaran dan senang dengan pembelajaran IPA terpadu tematik walaupun belum seutuhnya sesuai dengan yang diharapkan. Astin Lukum (2015) dalam penelitiannya yang berjudul evaluasi program pembelajaran IPA SMP menggunakan model countenance stake menyimpulkan bahwa hasil belajar peserta didik belum memenuhi kriteria ketuntasan minimal (KKM) dengan aktualitas ketercapaian 65\% kategori cukup, dikarenakan pembelajaran belum dilaksanakan sesuai dengan kenyataannya. Sehingga diperlukan pentingnya kesesuaian antara di lapangan dengan aturan yang berlaku.

Penelitian yang dilakukan oleh Nopy Widian Ningsih, et al., (2013) pengembangan perangkat pembelajaran IPA terpadu tipe webbed tema tercemarkah airku di kelas VII SMP menyatakan bahwa Kurikulum 2013 pada pembelajaran IPA terpadu tematik dapat terlaksana apabila semua perangkat pembelajarannya tersedia dengan baik dan dipahami oleh guru. 
Berdasarkan beberapa aspek penilaian yang telah dilakukan, dapat dideskripsikan bahwa keterlaksanaan pembelajaran IPA terpadu tematik di SMPN 1 Tambusai dengan rata-rata $75 \%$ dan dikategorikan baik. Sehingga SMPN 1 Tambusai sudah melaksanakan pembelajaran IPA secara terpadu tematik.

\section{Kesimpulan dan Saran}

Berdasarkan yang telah dilakukan dapat disimpulkan bahwa dari beberapa aspek penilaian yaitu aspek perancangan perencanaan pembelajaran IPA terpadu dengan persentase nilai $75 \%$ dikategorikan cukup, aspek pelaksanaan pembelajaran IPA terpadu dikategorikan cukup dengan persentase $72,5 \%$, dan aspek penilaian proses dan hasil belajar dengan persentase $77,5 \%$ dan dikategorikan baik. Sehingga rata-rata keseluruhan aspek yaitu $75 \%$ dan dikategorikan baik. Sehingga keterlaksanaan penerapan pembelajaran IPA terpadu tematik di SMPN 1 Tambusai sudah dilaksanakan dengan baik. Diharapkan pada penelitian selanjutnya yaitu dengan lebih memperhatikan pada penentuan tema, model keterpaduan yang diterapkan dan ketelitian serta menganalisis kompetensi dasar yang disediakan pemerintah agar pembelajaran lebih tepat sasaran.

\section{Daftar Pustaka}

Astin Lukum, 2015. Evaluasi Program Pembelajaran IPA SMP Menggunakan Model Countenance Stake. Jurnal Penelitian dan Evaluasi Pendidikan, Universitas Negeri Gorontalo, 19 (1), 25-37.

Daryanto, 2014. Pembelajaran Tematik, Terpadu, Terintegrasi (Kurikulum 2013). Gava Media, Yogyakarta.

Esmiyati, Sri Haryani, Eling Purwantoyo, 2013. Pengembangan Buku siswa IPA Terpadu Bervisi SETS (science, environment, technology, and society) Pada Tema Ekosistem. Unnes Science Education Journal: 2252-6609.
Fogarty, Robin, 1991. Ten Way to Integrate Curriculum IRI/Skylight Publishing, Inc., Illinois.

Friska Herina Fitriani, Parmin, Isa Akhlis, 2013. Pengembangan Media Pembelajaran IPA Terpadu Berbasis Komputer pada Tema Bunyi melalui Lesson Study Untuk Kelas VIII. Unnes Science Educational Journal, 2 (1). Prodi Pendidikan IPA Fakultas Matematika dan Ilmu Pengetahuan Alam Universitas Negeri Semarang,

Hendra Jati Puspita, 2016. Impelementasi Pembelajaran Tematik Terpadu Pada Kelas VB SD Negeri Tegalrejo 1 Yogyakarta. Jurnal Pendidikan Guru Sekolah Dasar Edisi 9 Tahun Ke-5 2016. PGSD Fakultas Ilmu Pendidikan Universitas Negeri Yogyakarta.

Indah Ratnasari, 2016. Analisis Pelaksanaan Kurikulum 2013 dalam Mata Pelajaran Matematika. Jurnal Publikasi Ilmiah. Jurnal Universitas Muhammadiyah Surakarta, Surakarta: Program Studi Pendidikan Matematika FKIP Universitas Muhammadiyah Surakarta.

La Iru \& La Ode Safiun Arihi, 2012. Analisis Penerapan Pendekatan, Metode, Strategi, dan Model-Model Pembelajaran. Multi Presindo, Yogyakarta.

Muhammad Abduh, Nugroho, Siskandar, 2014. Evaluasi Pembelajaran Tematik Dilihat Dari Hasil Belajar Siswa.Indonesian Journal of Curriculum and Educational Technology Studies IJCETS, 1 (1). Jurusan Teknologi Pendidikan, Fakultas Ilmu Pendidikan, Universitas Negeri Semarang.

Izzati, N., Hindarto, S, D., Pamelasari, 2013. Pengembangan Modul Tematik dan Inovatif Berkarakter pada Tema Pencemaran Lingkungan Untuk Siswa Kelas VII SMP Jurnal Pendidikan IPA Indonesia JPII 2(2) (2013) 183-188. Semarang:Prodi Pendidikan IPA FMIPA Universitas Negeri Semarang.

Kemendikbud, 2013. Permendikbud No. 57 tahun 2014 tentang Kurikulum 2013 Sekolah Dasar/Madrasah Ibtidaiyah. Kemendikbud, Jakarta.

Nahampun, Jeperis, 2013. Pembelajaran IPA pada Kurikulum 2013. https://jeperis. 
wordpress.com/2013/11/13/pembelajara n-ipa-pada-kurikulum-2013/

Nurhikmah, 2017. Pengembangan Buku Teks Pelajaran IPA Model Sequenced dengan Tema Sistem Adaptasi Tubuh Manusia terhadap Perubahan Suhu dan Pendekatan ESD. Tesis. Pascasarjana Pendidikan Fisika UNP, Padang.

Nopy Widian Ningsih, 2013. Pengembangan Perangkat Pembelajaran IPA Terpadu Tipe Webbed Tema Tercemarkah Airku di Kelas VII SMP. Jurnal Pendidikan Sains e-Pensa, $01 \quad$ (1) 54-59, Program Studi Pendidikan Sains FMIPA Universitas Negeri Surabaya.

Sungkono,2009. Pengembangan Bahan Ajar. Universitas Negeri Yogyakarta, Yogyakarta.
Trianto, 2012. Model Pembelajaran Terpadu. Bumi Aksara, Jakarta.

Ujang Sukandi, 2001. Belajar Aktif. Pusat Penerbit Universitas, Jakarta.

Uus Toharudin, Sri Hendrawati, \& Andrian Rustaman, 2011. Membangun Literasi Sains Siswa. Humaniora, Bandung.

Wiwik Nurul Hayati, 2012. Pengelolaan Pembelajaran Tematik di SD Djama'atul Ichwan Surakarta. Program Studi Manajemen Pendidikan Program Pascasarjana Universitas Negeri Surakarta, Surakarta.

Yamin, Martinis, 2006. Strategi Pembelajaran Berbasis Kompetensi. Gaung Persada Press, Jakarta. 